\title{
ASSOCIATION OF PERCEIVED STRESS AND COPING STRATEGIES WITH DEPRESSIVE SYMPTOMS IN STUDENTS AT A PRIVATE MEDICAL COLLEGE IN ISLAMABAD
}

\author{
Sawera Mansoor, Nadia Azad, Usama Bin Zubair*, Khalid Hayat Khan \\ Foundation University Medical College, Islamabad Pakistan, *The Mater Misericordiae University Hospital, Dublin, Ireland
}

\begin{abstract}
Objective: To determine the association of perceived stress and coping strategies with depressive symptoms in students at a private medical college in Islamabad.

Study Design: Correlational study.

Place and Duration of Study: Foundation University Medical College, Islamabad, from Jun to Dec 2019.

Methodology: Fourth and Final year medical students of Foundation university medical college were enrolled in the study. Beck's Depression Inventory was used to assess the depressive symptoms, perceived stress scale (PSS) was the tool used to look for the perceived stress and the coping strategies were assessed using the Brief Coping Orientation to Problems experienced (Brief COPE) Inventory. The association of perceived stress and coping strategies with depressive symptoms and other sociodemographic factors was established with the help of the chi-square test.

Results: Out of 262 medical students included in the study, 211 (80.5\%) had none or mild depressive symptoms while 51 $(19.5 \%)$ had moderate to severe depressive symptoms. Sixty-six (25.2\%) had low stress, 127 (48.4\%) had moderate stress while $69(26.3 \%)$ reported high stress levels. Pearson chi-square test revealed that perceived stress and the coping strategies used including self-distraction, active coping, denial, substance use, behavioural disengagement, positive reframing, acceptance, religion/spirituality and self-blaming had a statistically significant relationship with the presence of depressive symptoms among the target population.

Conclusion: Considerable number of medical students had the presence of moderate to severe depressive symptoms in our study. Perceived stress and some specific kinds of coping strategies had a significant association with the presence of depressive symptoms among the target population.
\end{abstract}

Keywords: Coping strategies, Depression, Medical students, Perceived stress.

How to Cite This Article: Mansoor S, Azad N, Zubair UB, Khan KH. Association of Perceived Stress and Coping Strategies with Depressive Symptoms in Students At A Private Medical College in Islamabad. Pak Armed Forces Med J 2021; 71(5): 1676-1681. doi: https://doi.org/10.51253/pafmj.v71i5.4770

This is an Open Access article distributed under the terms of the Creative Commons Attribution License (http://creativecommons.org/licenses/by/4.0), which permits unrestricted use, distribution, and reproduction in any medium provided the original work is properly cited.

\section{INTRODUCTION}

Medical education focuses on imparting knowledge, skills and attitudes to medical students to produce competent graduates. The environment at medical colleges is competitive and typically generates higher stress levels. Both academic and psychosocial stresses appear to play a role, and the resourceful students who are able to employ effective coping strategies to deal with their stress are shown to outperform their peers in the academic settings ${ }^{1,2}$. Previous literature has also highlighted the physical and psychological consequences of high-stress levels with limited coping ${ }^{3}$.

Depression has been studied among students of all levels in various settings ${ }^{4,5}$. Medical students have been no exception to this rule; thus, many local and foreign studies have highlighted the increased prevalence of depression among medical students ${ }^{6}$. Multiple

Correspondence: Dr Sawera Mansoor, Asst Prof of Psychiatry, Foundation University Medical College, Islamabad Pakistan

Received: 10 Jul 2020; revised received: 17 Sep 2020; accepted: 23 Sep 2020 biological, psychological and social reasons may be held responsible for this high prevalence but the key lies in early detection and prompt management in order to avoid the grave consequences of this potentially disabling condition. The concept of stress and coping become more relevant when some individual at vulnerable age is exposed to the continuous stress of a competitive environment along with other days to day stressors. The medical college environment fits perfectly into the above-mentioned description therefore medical students become highly vulnerable to developing maladaptive coping strategies which may affect their mental health and cause psychiatric morbidity.

The relationship between perceived stress, coping behaviours, burnout, and general psychopathology were explored at a tertiary care hospital in India. The authors found that postgraduate medical students with higher scores on general psychopathology and burnout also reported a greater perception of stress. Positive ways of coping with stress were reported to be helpful. Female students appeared to be at higher risk of being 
significantly stressed ${ }^{7}$. Similar findings were reported in a study on undergraduate medical students in Egypt where the prevalence of perceived stress was slightly higher $(88.9 \%)$ among medical students than among nonmedical students (83.5\%). Severe stress was found to be statistically significant among $(18.8 \%)$ of medical students compared to (12.4\%) among nonmedical students $^{8}$. Authors in Lebanon chose preclinical medical students to study stress, burnout and coping strategies. He reported a wide range of stress levels (between $20.9 \%$ and $90 \%$ ) among a variety of sample populations, while burnout ranged between $27-75 \%$. The authors suggested various psychosocial interventions to mitigate the stress and burnout levels, including an enhanced focus on personal growth and reactivating social networks for career guidance ${ }^{9}$. A cross-sectional assessment of stress, coping, and burnout in the finalyear medical undergraduate students in India identified a statistically significant association of stress with general psychopathology, the depression-anxiety subscale of burnout was also associated with perceived stress. Certain adaptive coping strategies like being able to accept the stressors, framing the problems in a positive light, planning a problem-solving approach and the use of humour was effectively being used to manage the stress levels in some students ${ }^{10}$. Therefore it appears that insight into coping activities used to overcome stress might be useful in our context also.

Ours is a country with a huge population, and a large number of private and public sector medical colleges enrol thousands of students each year. Though local studies have been done regarding depression among medical students, less attention has been paid to the relationship of depression with perceived stress, and what behaviours can be effectively used to cope with the stressors. Therefore, this study was planned to assess the levels of depressive symptoms in medical students and explore their association with the perception of stress and coping styles of these students.

\section{METHODOLOGY}

This cross sectional study was conducted at Foundation University Medical College, Islamabad, from June to December 2019. After formal ethics approval was obtained from the Institutional ethical review committee (Reference no. FF/FUMC/215-7 Phy/19 dated 24th May 2019), consecutive non-probability sampling was used to recruit the students for this study. Sample size was calculated by using the WHO sample size calculator by using population prevalence of significant stress in $20.9 \%$ of medical students ${ }^{11}$.
Inclusion Criteria: All students, male and female, aged 18 to 25 years enrolled in fourth and final year of their MBBS at Foundation University Medical College, Islamabad were enrolled in the study.

Exclusion Criteria: Students with already diagnosed psychiatric problems or those on psychiatric medications were excluded from the study. We also excluded students who had undergone any major bereavement in past 6 months to avoid recall bias while self- reporting stress and depressive features.

All study participants were informed about the title of the study and its objectives to assess the association of depressive symptoms with perceived stress and coping styles of medical students. The researchers obtained written informed consent from each participant, following which a serial reference number was each allocated for each person and it was recorded on their questionnaire booklet. In this way, the confidentiality and anonymity of every participant's data was ensured.

A demographic information form was prepared to record the relevant socio demographic variables including the age, gender, smoker/non-smoker status, day scholar/hostel boarder and monthly family income of the students participating in the research. The questionnaire scores at the end of the demographic form were entered later by the researcher after data collection was completed. The study participants were also requested to complete the questionnaire booklet and return it to the researcher. In addition to demographic information form, the questionnaire booklet contained the following measures.

Beck's Depression Inventory (BDI) is a widely used measure to assess the presence and severity of depressive symptoms. It is a standardized self-administered psychometric tool that consists of 21 items assessing the presence and severity of different domains of depression including the affective, cognitive, motivational and psychomotor symptomatology. A 4point likert scale (0-3) is used to rate all 21-items. The scoring sheet is as follows: 0-13 (no depression), 14-19 (mild depression), 20-28 (moderate depression) and 2963 (severe depression). Authors have previously used a cut off score of 21 to identify cases as having moderate to severe depressive symptoms ${ }^{12}$, and we used this cut off to categorize our sample population into 2 groups: 0-20 (No/mild depression) and 21 onwards (Moderate /Severe depression).

Perceived Stress Scale (PSS) has been widely used and psychometrically validated as a reliable measure 
of psychological stress estimated over the previous 4 weeks. It comprises of 10 items measured on a fivepoint Likert scale (0: never, 1 : almost never 2: sometimes 3: fairly often 4: very often). The PSS score is obtained by summing the scores of all the items, with reverse coding for items $4,5,7$, and 8 as they are positively stated. The PSS score ranges from $0-40$, with the 40 point score representing the highest perceived stress level. PSS categories: Low 0-13, Moderate 14-26 And High 27-4013.

Brief COPE Inventory consists of fourteen scales to identify different dimensions of coping strategies: 1) active coping, 2) planning, 3) using instrumental support, 4) using emotional support, 5) venting, 6) disengagement of behaviour, 7) self-distraction, 8) self-blame, 9) positive reframing, 10) humor, 11) denial, 12) acceptance, 13) religion, 14) substance use. Each scale is measured by two items, adding up to a total of 28 items in the Inventory ${ }^{14}$.

SPSS-20 was used to enter and analyze data. The variables in this study included: Age group, gender, smoker/non-smoker, resident status (day scholar/ hostel boarder), monthly family income, scores on Beck Depression Inventory (BDI), Perceived Stress Scale (PSS) and Brief COPE Inventory. Mean, standard deviation and percentages were used to describe the summary of study variables. The categorical variables were analyzed using the chi-square test to assess the variance between the groups. The $p$-value of $<0.05$ was considered as significant.

\section{RESULTS}

A total of 262 fourth and final year medical students were included in the study with a mean age of 22.8 years $\pm 1.15 \mathrm{SD}$. Seventy-six $(29 \%)$ were males and $186(71 \%)$ were females, and only $19(7.3 \%)$ were smokers while $243(92.7 \%)$ reported themselves as nonsmokers. The majority of students in our sample were day scholars $191(72.9 \%)$ and $71(27.1 \%)$ resided in the college hostel. Out of the 262 medical students studied, $211(80.5 \%)$ had no or mild depressive symptoms while $51(19.5 \%)$ had more serious depressive symptomatology falling in the moderate to severe category. There was no statistical significance in the association of the relevant socio-demographic variables (age, gender, smoker/non-smoker status, day scholar/hostel boarder) with depressive symptomatology.

Table-I shows that 66 (25.2\%) of the total students had low stress, 127 (48.4\%) had moderate stress while $69(26.3 \%)$ had high stress, and perceived stress has a strong relationship with depressive symptomatology among the study participants ( $p$-value $<0.001$ ).

The most commonly used coping strategies were active coping (53.8\%), religion/spirituality $(53.4 \%)$ and planning $(51.9 \%)$, while substance use $(4.6 \%)$, behavioural disengagement (14.9\%) and Denial (15.3\%) were the least commonly used by the students in our study. Pearson chi-square test revealed that self-distraction, active coping, denial, use of harmful substances, behavioural disengagement, reframing events positively, acceptance, religion/spirituality and self-blaming had a statistically significant relationship ( $p$-value $<0.05)$ with the presence of depressive symptoms among the target population (table-II).

\section{DISCUSSION}

Stress is an integral part of everyone's life. Coping strategies adopted by the individual to cope with the stress and the stressors themselves are integral in determining the effect of stresses on his mental health and overall quality of life $^{2}$. We planned this study to determine the association of perceived stress and coping strategies with depressive symptoms in students at a private medical college in Islamabad.

Out of all 262 students made part of the sample, $211(80.5 \%)$ had no or mild depressive symptoms while $51(19.5 \%)$ had moderate to severe depressive symptoms. Our finding is consistent with the outcome of a meta-analysis published in 2016 where Puthran et al, evaluated the prevalence of depressive illness amongst medical students globally. The authors also reported that almost one-third of medical students around the world are affected by Depression ${ }^{15}$.

The medical students included in our study were from the clinical fourth and final years. The majority of our students reported moderate and high levels of stress, and only $25.2 \%$ perceived their stress to be below. This finding is similar to the conclusions drawn by Anuradha et al, in 2017 in a study planned to assess the perception of stress among medical undergraduate students. The authors asked about the sources of stress, and the associated relevant socio-demographic factors were also identified ${ }^{16}$. The authors concluded that the more senior students in the higher age group and those in their final year of education perceived higher levels of stress, thus corroborating our finding of higher stress levels in medical students during their clinical years.

A similar study among medical students of Jeddah, KSA concluded that the majority of their study 
participants reported frequently occurring stressful events and high-stress levels were found in $59.2 \%$ of the students ${ }^{17}$. This is consistent with our finding where around $69 \%$ of our students had moderate to a high level of perceived stress, and perceived stress had a strong relationship with the presence of depression among our study participants as well.

Given the high stress reported by medical

Table-I: Association of perceived stress with depressive symptomatology.

\begin{tabular}{|c|c|c|c|c|c|}
\hline Perceived Stress & $\begin{array}{l}\text { No / Mild Depression } \\
\text { n }(\%), 211(80.5 \%)\end{array}$ & $\begin{array}{c}\text { Moderate/ Severe Depression } \\
\mathrm{n}(\%), 51(19.5 \%)\end{array}$ & $\begin{array}{c}\text { Total } \\
\text { n (\%), } 262(100 \%)\end{array}$ & $x^{2}$ & $p$-value \\
\hline Low stress & $60(22.9 \%)$ & $6(2.3 \%)$ & $66(25.2 \%)$ & \multirow{3}{*}{34.658} & \multirow{3}{*}{$>0.001$} \\
\hline Moderate stress & $112(42.7 \%)$ & $15(5.7 \%)$ & $127(48.5 \%)$ & & \\
\hline High stress & $39(14.9 \%)$ & $30(11.5 \%)$ & $69(26.3 \%)$ & & \\
\hline \multicolumn{6}{|c|}{ Table-II: Association of coping strategies with depressive symptomatology. } \\
\hline $\begin{array}{l}\text { Coping } \\
\text { Strategies }\end{array}$ & $\begin{array}{l}\text { No / Mild Depression } \\
\text { n }(\%), 211(80.5 \%)\end{array}$ & $\begin{array}{c}\text { Moderate/ Severe Depression } \\
\text { n (\%), } 51(19.5 \%)\end{array}$ & $\begin{array}{c}\text { Total } \\
\text { n }(\%), 262(100 \%)\end{array}$ & $x^{2}$ & $p$-value \\
\hline \multicolumn{6}{|l|}{ Self-Distraction } \\
\hline Yes & $81(30.9 \%)$ & $29(11.1 \%)$ & $110(42 \%)$ & \multirow{2}{*}{5.755} & \multirow{2}{*}{0.016} \\
\hline No & $130(49.6 \%)$ & $22(8.4 \%)$ & $152(58 \%)$ & & \\
\hline \multicolumn{6}{|l|}{ Active Coping } \\
\hline Yes & $120(45.8 \%)$ & $21(8 \%)$ & $141(53.8 \%)$ & \multirow{2}{*}{4.071} & \multirow{2}{*}{0.044} \\
\hline No & $91(34.7 \%)$ & $30(11.5 \%)$ & $121(46.2 \%)$ & & \\
\hline \multicolumn{6}{|l|}{ Denial } \\
\hline Yes & $22(8.4 \%)$ & $18(6.9 \%)$ & $40(15.3 \%)$ & \multirow{2}{*}{19.634} & \multirow{2}{*}{$>0.001$} \\
\hline No & $189(72.1 \%)$ & $33(12.6 \%)$ & $222(84.7 \%)$ & & \\
\hline \multicolumn{6}{|c|}{ Use of Emotional Support } \\
\hline Yes & $107(40.8 \%)$ & $21(8 \%)$ & $128(48.9 \%)$ & \multirow{2}{*}{1.494} & \multirow{2}{*}{0.222} \\
\hline No & $104(39.7 \%)$ & $30(11.5 \%)$ & $134(51.1 \%)$ & & \\
\hline \multicolumn{6}{|c|}{ Use of Instrumental Support } \\
\hline Yes & $43(16.4 \%)$ & $10(3.8 \%)$ & $53(20.2 \%)$ & \multirow{2}{*}{0.015} & \multirow{2}{*}{0.902} \\
\hline No & $168(64.1 \%)$ & $41(15.6 \%)$ & $209(79.8 \%)$ & & \\
\hline \multicolumn{6}{|l|}{ Substance Use } \\
\hline Yes & $7(2.7 \%)$ & $5(1.9 \%)$ & $12(4.6 \%)$ & \multirow{2}{*}{3.954} & \multirow{2}{*}{0.047} \\
\hline No & $204(77.9 \%)$ & $46(17.6 \%)$ & $250(95.4 \%)$ & & \\
\hline \multicolumn{6}{|c|}{ Behavioural Disengagement } \\
\hline Yes & $16(6.1 \%)$ & $23(8.8 \%)$ & $39(14.9 \%)$ & 45624 & $>0001$ \\
\hline No & $195(74.4 \%)$ & $28(10.7 \%)$ & $223(85.1 \%)$ & $40.0 \angle 4$ & $>0.001$ \\
\hline Venting & & & & & \\
\hline Yes & $88(33.6 \%)$ & $27(10.3 \%)$ & $115(43.9 \%)$ & & \\
\hline No & $123(46.9 \%)$ & $24(9.2 \%)$ & $147(56.1 \%)$ & 2.105 & 0.147 \\
\hline Positive Reframi & & & & & \\
\hline Yes & $111(42.4 \%)$ & $18(6.9 \%)$ & $129(49.2 \%)$ & 4025 & 0026 \\
\hline No & $100(38.2 \%)$ & $33(12.6 \%)$ & $133(50.8 \%)$ & $4.9<0$ & $0.0 \angle 0$ \\
\hline Planning & & & & & \\
\hline Yes & $115(43.9 \%)$ & $21(8 \%)$ & $136(51.9 \%)$ & 2922 & 0087 \\
\hline No & $96(36.6 \%)$ & $30(11.5 \%)$ & $126(48.1 \%)$ & $2.9 \angle 2$ & $0.08 /$ \\
\hline Humor & & & & & \\
\hline Yes & $41(15.6 \%)$ & $9(3.4 \%)$ & $50(19.1 \%)$ & 0085 & 0771 \\
\hline No & $170(64.9 \%)$ & $42(16 \%)$ & $212(80.9 \%)$ & 0.085 & 0.771 \\
\hline Acceptance & & & & & \\
\hline Yes & $98(37.4 \%)$ & $15(5.7 \%)$ & $113(43.1 \%)$ & 4859 & 0028 \\
\hline No & $113(43.1 \%)$ & $36(13.7 \%)$ & $149(56.9 \%)$ & 4.859 & 0.028 \\
\hline Religion/Spiritua & & & & & \\
\hline Yes & $121(46.2 \%)$ & $19(7.3 \%)$ & $140(53.4 \%)$ & 6663 & 0010 \\
\hline No & $90(34.4 \%)$ & $32(12.2 \%)$ & $122(46.6 \%)$ & 6.663 & 0.010 \\
\hline Self Blaming & & & & & \\
\hline Yes & $65(24.8 \%)$ & $25(9.5 \%)$ & $90(34,4 \%)$ & & \\
\hline No & $146(55.7 \%)$ & $26(9.9 \%)$ & $172(65.6 \%)$ & 6.042 & 0.014 \\
\hline
\end{tabular}


students, the role of effective coping behaviours becomes an important variable to be studied. Tartas et al, conducted interesting research in 2016 to focus on the coping strategies employed by students, and their relation to the success of the future academic profile of the students during the course of their medical education. They came up with the conclusion that it can be useful to assess commonly used coping strategies of newly inducted medical students, and they may be an indication of the career path of medical students ${ }^{18}$. We also explored various strategies used by our students to cope with stress; amongst healthier coping behaviours we found self-distraction, active coping, reframing in a positive light, accepting stressful events, and an inclination to rely on religion and spirituality were effective ways to deal with the negative impact of stress leading to lower depressive symptoms. We found that the majority of students employed religious beliefs and practices to manage stressful circumstances. This is an expected finding in our local socio-cultural context where the pillars of faith are a pivotal part of life for most of the population. Similar to our findings, a study conducted at a medical college in Saudi Arabia also reported blaming oneself and being self-critical was associated with higher stress, and finding comfort in religion as the main coping strategy was inversely associated with stress levels ${ }^{19}$.

Some students in our study engaged in the maladaptive strategies of denial, behavioural disengagement and self-blaming, these were also found to have a statistically significant relationship with the presence of depressive symptoms among the target population. Likewise, a recent study conducted to assess depression and anxiety symptoms in 2057 medical students in China highlighted a positive correlation between negative coping styles and depression ${ }^{20}$. The authors concluded that medical students should be supported to adopt more positive coping to mitigate the effects of anxiety and depression.

Stress and coping styles in postgraduate medical students of India were evaluated and the authors reported that higher stress levels scored on PSS along with the use of unhealthy coping styles were positively correlated with psychological morbidity ${ }^{21}$. Our results did not reflect the relationship of stress with coping but we analyzed the relationship of depressive symptoms with various coping strategies, and many maladaptive coping strategies were significantly linked with depression among the medical students in our study. These findings point towards a need to screen students using unhealthy coping behaviours to manage stress, so that they can be provided early appropriate support to offset depressive symptomatology.

Self-administered questioners may raise bias associated with under or over-reporting of symptoms which has been one of the main limitations of our study. Moreover, students of only one private medical college in Islamabad were targeted for the study. Results may change if the sample size increase and a multi-centre study are performed.

\section{CONCLUSION}

A considerable number of medical students had the presence of moderate to severe depressive symptoms in our study. Perceived stress and some specific kinds of coping strategies had a significant association with the presence of depressive symptoms among the target population.

\section{Conflict of Interest: None.}

\section{Authors' Contribution}

SM: Conception and design of study, Collection and assembly of data, Drafting of article, Critical revision for intellectual component Statistical expertise, Final approval and guarantor, NA: Conception and design of study, Collection and assembly of data, Critical revision for intellectual component, Final approval and guarantor, UBZ: Conception and design of study, Drafting of article, Statistical expertise, Final approval and guarantor, KHK: Conception and design of study, Critical revision for intellectual component, Final approval and guarantor.

\section{REFERENCES}

1. Al-Dubai SA, Al-Naggar RA, Alshagga MA, Rampal KG. Stress and coping strategies of students in a medical faculty in Malaysia. Malays J Med Sci 2011; 18(3): 57-64.

2. Sreeramareddy CT, Shankar PR, Binu VS, Mukhopadhyay C, Ray B, Menezes RG. Psychological morbidity, sources of stress and coping strategies among undergraduate medical students of Nepal. BMC Med Educ 2007; 7(1): 26-29.

3. Imran N, Tariq KF, Pervez MI, Jawaid M, Haider II. Medical students' stress, psychological morbidity, and coping strategies: a cross-sectional study from Pakistan. Acad Psychiatr 2016; 40(1): 92-96.

4. Zubair UB, Ali U. Prevalence of depressive symptoms and associated socio-demographic factors among intermediate college boys. Austin J Psychiatr Behav Sci 2015; 2(2): 1040-45.

5. Zubair UB, Mansoor S. Prevalence of depressive symptoms and associated socio-demographic factors among recruits during military training. BMJ Military Health 2015; 161(1): 127-31.

6. Mao Y, Zhang N, Liu J, Zhu B, He R, Wang X. A systematic review of depression and anxiety in medical students in China. BMC Med Educ 2019; 19(1): 327-30.

7. Guruprakash KV, Mehta SG, Atul B, Prakash J, Divinakumar KJ, Khan SA, et al. A study of the relationship between perceived stress, coping pattern, burnout, and general psychopathology among the postgraduate medical students. Ind Psychiatr J 2018; 27(1): 141-46. 


\section{Perceived Stress and Depression Coping Strategies}

8. Seedhom AE, Kamel EG, Mohammed ES, Raouf NR. Predictors of Perceived Stress among Medical and Nonmedical College Students, Minia, Egypt. Int J Prev Med 2019; 10(1): 107-10.

9. Fares J, Al Tabosh H, Saadeddin Z, El Mouhayyar C, Aridi H. Stress, burnout and coping strategies in preclinical medical students. N Am J Med Sci 2016; 8(2): 75-81.

10. Singh S, Prakash J, Das RC, Srivastava K. A cross-sectional assessment of stress, coping, and burnout in the final-year medical undergraduate students. Ind Psychiatr J 2016; 25(2): 179-83.

11. Yusoff MS, Abdul Rahim AF, Yaacob MJ. Prevalence and sources of stress among university sains malaysia medical students. Malays J Med Sci 2010; 17(1): 30-37.

12. Park K, Jaekal E, Yoon S, Lee SH, Choi KH. Diagnostic utility and psychometric properties of the beck depression inventory-II among Korean adults. Front Psychol 2020; 10(1): 2934-38.

13. Party R, Basu S, Meena GS, Banerjee B. Perceived stress and its epidemiological and behavioural correlates in an urban area of Delhi, India: a community-based cross-sectional study. Indian J Psychol Med 2020; 42(1): 80-86.

14. Muller L, Spitz E. Evaluation multidimensionnelle du coping: validation du Brief COPE sur une population française [multidimensional assessment of coping: validation of the Brief COPE among French population]. Encephale 2003; 29(6): 507-18.

15. Puthran R, Zhang MW. Prevalence of depression amongst medical students: a meta-analysis. Med Educ 2016; 50(4): 456-68.
16. Anuradha R, Dutta R, Raja JD, Sivaprakasam P, Patil AB. Stress and stressors among medical undergraduate students: a crosssectional study in a Private Medical College in Tamil Nadu. Ind J Commun Med 2017; 42(4): 222-25.

17. Gazzaz ZJ, Baig M, Al Alhendi BSM, Al Suliman MMO, Al Alhendi AS, Al Grad MSH, et al. Perceived stress, reasons for and sources of stress among medical students at Rabigh Medical College, King Abdulaziz University, Jeddah, Saudi Arabia. BMC Med Educ 2018; 18(1): 29-32.

18. Tartas M, Walkiewicz M, Budziński W, Majkowicz $M$, Wójcikiewicz K, Zdun-Ryżewska A. The coping strategies during medical education predict style of success in medical career: a 10-year longitudinal study. BMC Med Educ 2016; 16(2): 186-89.

19. Bamuhair SS, Al Farhan AI, Althubaiti A, Agha S, Rahman S, Ibrahim NO. Sources of stress and coping strategies among undergraduate medical students enrolled in a problem-based learning curriculum. J Biomed Educ 2015: 1(1); 1-8.

20. Shao R, He P, Ling B, Tan L, Xu L, Hou Y, et al. Prevalence of depression and anxiety and correlations between depression, anxiety, family functioning, social support and coping styles among Chinese medical students. BMC Psychol 2020; 8(1): 38.

21. Datar MC, Shetty JV, Naphade NM. Stress and coping styles in postgraduate medical students: A medical college-based study. Int J Soc Psychiatr 2017; 33(4): 370-74. 